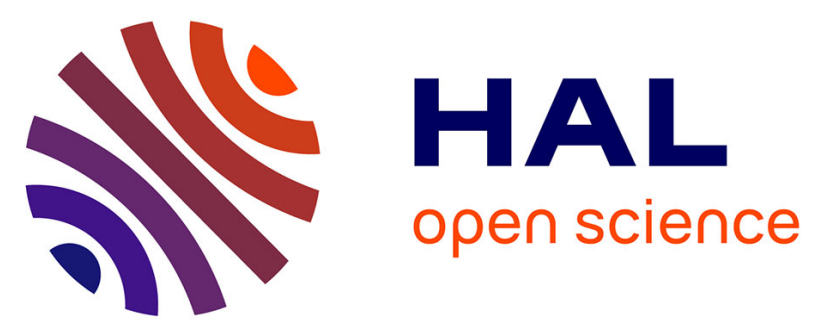

\title{
Monitoring of irrigated wheat in a semi-arid climate using crop modelling and remote sensing data: Impact of satellite revisit time frequency
}

R. Hadria, Benoît Duchemin, A. Lahrouni, S. Khabba, S. Er Raki, Gérard Dedieu, Ghani Chehbouni, Albert Olioso

\section{To cite this version:}

R. Hadria, Benoît Duchemin, A. Lahrouni, S. Khabba, S. Er Raki, et al.. Monitoring of irrigated wheat in a semi-arid climate using crop modelling and remote sensing data: Impact of satellite revisit time frequency. International Journal of Remote Sensing, 2006, 27 (5-6), pp.1093-1117. 10.1080/01431160500382980 . ird-00389480

\section{HAL Id: ird-00389480 \\ https://hal.ird.fr/ird-00389480}

Submitted on 28 May 2009

HAL is a multi-disciplinary open access archive for the deposit and dissemination of scientific research documents, whether they are published or not. The documents may come from teaching and research institutions in France or abroad, or from public or private research centers.
L'archive ouverte pluridisciplinaire HAL, est destinée au dépôt et à la diffusion de documents scientifiques de niveau recherche, publiés ou non, émanant des établissements d'enseignement et de recherche français ou étrangers, des laboratoires publics ou privés. 


\title{
Monitoring of irrigated wheat in a semi-arid climate using crop modelling and remote sensing data : Impact of satellite revisit time frequency
}

\author{
R. HADRIA ${ }^{*} \uparrow$, B. DUCHEMIN $\dagger+$, A. LAHROUNI $\dagger$, S. KHABBA $\dagger$, S. ER-RAKI†, G. \\ DEDIEU:, A.G. CHEHBOUNI†‡, A. OLIOSO $\neq$ \\ $\dagger$ FSSM - Faculté des Sciences Semlalia, Université Cadi Ayyad, Avenue Prince My \\ Abdellah, BP 2390, Marrakech - Maroc. \\ † CESBIO - Centre d'Etudes Spatiales de la Biosphère, 18 Avenue Edouard Belin, bpi 2801, \\ 31401 Toulouse cedex 9, France. \\ ₹ INRA - Institut National de Recherche Agronomique, Département : Environnement et \\ Agronomie, UMR : CSE, Site Agroparc, 84914 Avignon Cedex 9, France \\ *Corresponding author: r.hadria@ucam.ac.ma
}

\begin{abstract}
The rationale of this research is to investigate approaches based on modelling and remote sensing data for estimating the spatial distribution of yield and irrigation of wheat in semi-arid areas. The specific objective is to compare the performances of two approaches to test the STICS crop model using remotely sensed estimates of Leaf Area Index (LAI).
\end{abstract}

An experimental study of phenology, yield and water balance of an irrigated wheat was made in the Marrakech-Haouz plain during year 2003. Experimental data allowed to run STICS using two approaches: 1) calibration of the parameters that control the 
time course of LAI ; 2) driving from LAI time series interpolated with a simple model. The results show the accuracy of STICS to simulate actual evapotranspiration and yield for both approaches.

Finally, the two approaches were compared using remotely sensed estimates of LAI upon four scenarios of satellite time revisit frequency. The simulations we obtained always show acceptable results. However, differences appear between the variables, between the approaches and between the frequencies.

Keywords: STICS crop model; calibration; semi arid; wheat; evapotranspiration; yield.

\section{Introduction}

In the semi-arid Haouz plain that surrounds the city of Marrakech (Centre of Morocco), water availability is one of the main factors that controls crop vigour and yield. Indeed, the evaporative demand - around $1600 \mathrm{~mm}$ per year according to reference evapotranspiration estimates (Allen 2000) - is very large when compared with rainfall, which are about $240 \mathrm{~mm}$ per year. In this context, a critical term to be monitored is the surface actual evapotranspiration (AET). This is particularly true in semi-arid flat areas where rainfall and irrigation supply are generally so low than runoff, drainage and deep percolation can be neglected. Consequently, AET remains the dominating term which controls the soil water balance. An accurate estimation of this variable for wheat, the main irrigated cereal crop around Marrakech, would present a first step to schedule irrigation in order to save water while sustaining the production.

In Morocco, cereals have covered 59\% of ploughed area during the 1990-2000 decade (Karrou 2003). Therefore, the monitoring of cereal irrigation and water balance 
at a regional scale is a major challenge for a sustainable development of agriculture. In this regard, the SudMed project (Chehbouni et al. 2003) has focused, amongst several approaches, on the combination of crop models and remote sensing data.

Crop models simulate the relations between soil, plant and atmosphere in order to predict biomass components and grain yield. They can be used to monitor the plant phenology as well as to evaluate yield and water use in many agricultural applications. They are useful to evaluate the crop response to environmental stress, e.g. drought, in complement with field experiments. For these reasons, the number of crop models has increased within the scientific community: there are models for particular crop, e.g. ARCWHEAT (Weir et al. 1984) or CERES-Wheat (Ritchie and Otter 1985), as well as generic models, e.g. EPIC (Williams et al. 1989) or DAISY (Hansen et al. 1990). In spite of the fact that many of these models have been designed to operate at the field scale, most of them have been already tested at larger scale (Guérif and Duke 1998, 2000, Clevers et al. 2002, Prévot et al. 2003).

Although the use of crop model at a regional scale presents many assets for agricultural decision-makers, shortage of input data at the appropriate space-time scales represents a major limitation for operational use (Guérif and Duke 1998, Moulin and Guérif 1999). For agricultural applications such as regional yield estimation (Arkin et al. 1980) and irrigation scheduling (Harris and Mapp 1980), the combination of a minimum of inputs is favoured. Additionally, remote sensing can contribute to the knowledge of some key-variables of crop models, and especially their time and space variation (Moulin et al. 1998, Kimes et al. 2000, Kite and Droogers 2000, Schmugge et al. 2002). There are many possibilities to use in conjunction crop models and satellite data, based on driving, calibration or assimilation techniques (Olioso et al. 1999, 
Jacquemoud et al. 2000, François et al. 2001, Weiss et al. 2001, Combal et al. 2003, Moulin et al. 2003, Verhoef and Bach 2003, Boegh et al. 2004, Demarty et al. 2004, Mo et al. 2004, Pellenq and Boulet 2004).

In the optical part of the spectrum, the properties of surface reflectances have been heavily investigated. As a result, several methods have been developed to monitor crop biophysical variables such as the leaf area index (LAI) or the fraction of photosynthetically active radiation that is absorbed by the vegetation (Baret and Guyot 1991, Gutman and Ignatov 1995, Hall et al. 1995, Asner et al. 1998). At the present time, two types of images are provided by Earth Observation Systems : large field-ofview sensors such as VEGETATION (http://www.spot-vegetation.com), MERIS (http://envisat.esa.int/instruments/meris/) or MODIS (http://modis.gsfc.nasa.gov/) provide a global observation on a daily basis at $1 \mathrm{~km}$ spatial resolution, while decametric spatial resolution sensors such as SPOT (http://www.spotimage.fr/) or Landsat-TM (http://geo.arc.nasa.gov/sge/landsat/landsat.html) observe with a basic 15to 30-day revisit frequency. However, thanks to the constellation of SPOT satellites and their off-nadir viewing capabilities, it is possible to obtain an image on specific Earth places, nearly each day. It is a challenge for future missions to reach systematically this repetitivity with a high spatial resolution around $10 \mathrm{~m}$, following the design concept of ROCSAT (Chern et al. 2001) or RHEA (Dedieu et al. 2003) missions.

The rationale of this research is to investigate approaches based on modelling and remote sensing data for estimating the spatial distribution of yield and irrigation of wheat crops in the Marrakech-Haouz plain. The specific objective of this study is to compare the performances of two approaches to test a crop model using remotelysensed estimates of LAI under various time revisit capabilities of Earth Observation 
Systems. This work is based on simulated satellite data and the STICS (Simulateur mulTIidisciplinaire pour les Cultures Standard) crop model (Brisson et al. 1998, 2002, 2003), with a particular focus on three variables (LAI, AET and yield). Satellite data have been simulated from an experimental data set (ground-based radiometer) collected on one irrigated wheat field in the semi-arid Marrakech-Haouz plain.

\section{Material}

The area of interest is located in the Haouz plain, Centre of Morocco, $40 \mathrm{~km}$ East from the Marrakech city. The field of study was monitored during the 2002/2003 agricultural season. A full description of the experiment can be found in Duchemin et al. (2005) and in Hadria et al. (2005). It is referred to as "field I" in Duchemin et al. (2005) and "field C3" in Hadria et al. (2005), which describe the experiment. These experiment data have allowed us to collect the data required to run and validate the STICS model. A brief description of the material of interest for this particular study is given below, with an emphasis on the LAI-NDVI relationship and on the cloudiness analysis which have provided the basis to simulate remote sensing data. The STICS crop model is introduced at the end of this section.

\subsection{Experimental data on the field of study}

The field of study was sown on day of year 11 with a short duration durum wheat variety (Karim) over 4 ha. After sowing, irrigation water was supplied six times on average every 20 days, by flooding. Fertilizers were applied at the beginning of grain filling phase. At the end of May, final grain yield was estimated to $2 \mathrm{t} / \mathrm{ha}$ by a visual estimates of ORMVAH (Office Regional de Mise en Valeur Agricole du Haouz) 
technicians. This value is lower than that obtained in many other sites (Jamieson et al. 1998a, Clevers et al. 2002, Rodriguez et al. 2004), but it matches that observed on average for Morocco (Karrou 2003). The probable explanation is linked to the absence of fertilization during the growing phase (Hadria et al. 2005).

The climate is basically of a semi-arid continental type (Duchemin et al. 2005, Hadria et al. 2005), with a high contrast between rainfall $(200 \mathrm{~mm})$ and the climatic evaporative demand $(540 \mathrm{~mm})$. The surface energy and water balances of the field of study were intensively monitored from March to May 2003. The evapotranspiration was obtained from the energy balance equation using sensible heat flux collected from a 2meter tower equipped with an eddy covariance system (Ultrasonic Anemometer Model 81000, R.M. Young company, USA). 43 days of measurements have been available for this study, which have been recorded from days of year 79 to 123 (114 and 115 being missing). According to the first analysis of these data (Duchemin et al. 2005), no severe water-stress has occurred during the period of measurement. The problem of advection has been neglected since the field of study was surrounded with others wheat fields which have been managed with coherent agricultural practices by the same farmer (Fields C to I in Duchemin et al. 2005).

\subsection{LAI and NDVI}

The LAI-NDVI relationship we used in this study is based on the formalism proposed by Baret et al. (1989) and its calibration was performed by Duchemin et al. (2005). The LAI was derived from observations of leaves density and size on small square plots sampling. This technique provides direct and accurate estimates, but it is very time-consuming and very local. The NDVI (for Normalized Difference Vegetation 
Index) was derived from surface reflectances measured with a hand-held multispectral radiometer (MSR87, Cropscan, Inc., USA) with the spectral bands of Landsat-TM sensors. On a weekly basis, surface reflectances are collected along several transects every 10 meters. This technique has allowed to rapidly sample a large surface (around $40 \mathrm{~m}^{2}$ ) of the field of study, 14 times between sowing and maturity. The cross comparison has allowed to establish the exponential relationship between NDVI and LAI (eq. 1).

$$
N D V I=N D V I \infty+(N D V I s-N D V I \infty) * \exp ^{-K^{*} L A I}
$$

Where: $N D V I \infty=0.93$ for an "infinitely-dense" canopy; NDVIs $=0.14$ for dry bare soil; and $K=0.54$ is the light extinction coefficient. These values are discussed in Duchemin et al. (2005).

[Insert Figure 1 about here]

Figure 1, extracted from Duchemin et al. (2005), shows the LAI-NDVI relationship. The NDVI and LAI were found highly correlated, but the performance of the relationship was poor at high values because the NDVI saturates when the vegetation is totally covering the soil. This is consistent with previous results (Asrar et al. 1984, Baret et al. 1989, Richardson et al. 1992, Weiss and Baret 1999).

\subsection{Cloudiness}

In order to get realistic simulation of remote sensing data, we analysed time series of cloud occurrence using a global radiation data set recorded at seven meteorological stations spread over the Haouz plain. These stations have been installed in the frame of the SudMed project after summer 2002. From these data, we have studied the cloudiness at the crossing time of most of Earth Observation Systems, around $11 \mathrm{~h}$ local 
solar time. The clear-sky incoming radiation was computed following Allen et al. (1998), then a day was declared cloudy if the observed incoming radiation was lower by $30 \%$ than the clear-sky value. This provides with a binary flag (cloudy/cloud-free) for each day and for all the meteolorogical stations. The cloudiness analysis was performed from these time series using 30-day window, i.e. considering for the $\mathrm{D}$ day all observations of the sky status between day $\mathrm{D}-15$ and day $\mathrm{D}+15$. It has allowed us to characterise the probabilities of cloud occurrence and the transition in sky status from one day to the next, e.g. the probability that the day following a cloud-free day was cloudy.

Figure 2 shows the variation of these probabilities from January to May, along with the monthly cumulated rainfall observed in Marrakech during the last century. The cloud occurrence probability ranges between 20 and $45 \%$ in coherence with rainfall, e.g. maximum value of rainfall (35 $\mathrm{mm}$ in March) corresponds to maximum cloud occurrence. All the transition probabilities looks more or less constant except the one associated to stable clear conditions (see the probability that the day following a cloudfree day was cloud-free, highlighted in Figure 2), which knows a peak at the end of January that witnesses for long sunny periods. This is coherent with the occurrence of the two 'rainy' seasons in the area of study, the first one in November-December and the second one in March-April.

[Insert Figure 2 about here]

\subsection{The STICS crop model and basic parameters}

This work is based on the STICS crop model. Its theory and parameterization have been detailed in Brisson et al. (1998, 2002), and a sensitivity analysis has been 
performed by Ruget et al. (2002). The last version (version 5.0), which was used here, has been presented in Brisson et al. (2003). Our previous works (Duchemin et al. 2003, Rodriguez et al. 2004, Hadria et al. 2005) as well as others studies (Baret et al. 2002, Prévot et al. 2003) showed that the STICS crop model combines accuracy in its simulation and easiness in use with remote sensing data. Indeed, the LAI is a keyvariable of the model, which controls for a large part AET and yield and which can be monitored from remotely-sensed data.

The STICS parameters can be grouped into four classes: crop management, climate, soil and plant characteristics. All the parameters of the model were kept at their standard values, which are furnished with the 5.0 version of the software, except some main parameters, which have been adapted to the field of study. In addition to the sowing date, amount and time of irrigation and fertilizer, these parameters include the rate of foliage production and the thermal units between phenological stages in case of calibration approach. In the case of driving approach, only the thermal duration between plant emergence and beginning of grain filling stages were adjusted. The adaptation of these parameters is detailed in Hadria et al. (2005). These parameters are common to all the simulations we have performed.

\section{Methodology}

The simulation scheme follows the three steps summarised in Figure 3 :

[Insert Figure 3 about here]

1) The STICS model was first tested against LAI field observations in order to get several runs named "reference simulations" (top part from left to right in Figure 3). Two approaches are compared to run the model: calibration and driving. In the calibration 
approach, we adjusted one parameter of the STICS, in addition to the main phenological stages, in order to minimise the difference between observed and simulated LAI. In the driving approach, LAI time series are interpolated at a daily span step then used as an input variable to drive the STICS model.

2) Both approaches provide with LAI time courses at a daily step, which are used to simulate satellite data in a second step (middle part from right to left in Figure 3). The satellite data are processed through an algorithm that results in LAI time series referred to as "degraded LAI", because some data are missing or inaccurate. The algorithm is believed to simulate both observation errors due to uncertainty in the atmospheric correction and data losses due to the presence of clouds or the absence of satellite observations.

3) Finally, the STICS model was tested with degraded LAI inputs to obtain numerous runs referred to as "degraded simulations" (bottom part from left to right in Figure 3).

\subsection{Reference simulation - Calibration approach}

In addition to the phenological stages, there are numerous parameters that control the LAI time course in the STICS model. In Rodriguez et al. (2004) we calibrated four parameters based on the analysis of Brisson et al. (2002), Baret et al. (2002) and Ruget et al. (2002). Our recent works (Hadria et al 2005) have shown that the rate of foliage production is the key parameter to be adjusted. This parameter was optimised against LAI field observations using the Simplex algorithm (Nelder and Mead 1965), which is available in the version 5.0 of the STICS model. This approach is referred as SC1 as 
one parameter of STICS is Calibrated. It provides with one reference simulation providing LAI and AET time series associated to a final yield value.

\subsection{Reference simulations - Driving approach}

In parallel to the calibration approach, we tested the STICS model when it is driven by LAI. In this case, the LAI time course is not simulated by STICS but provided to it as an input. This approach presents the advantage that the characterisation of the vegetative phenological stages not have to be known. However, it is necessary to use an interpolator of LAI field observations in order to have LAI time series at the daily span of the STICS model. For this purpose, the simple model presented in the appendix A was used. Two methods have been tested according to the number of parameters we adjust to perform the interpolation. The first one is based on the adjustment of all the seven parameters of the simple model, while in the second one three parameters have been taken constant : the date of plant emergence, the light-use efficiency and the initial LAI value.

In a second step, the daily LAI time series have been provided to STICS as an input, then the thermal duration between plant emergence and beginning of grain filling stages is adjusted. This approach provides with two additional reference simulations of LAI, yield and AET, using two methods which are referred to as SD4 and SD7 (for STICS Driving and according to the number of parameters of the simple model we adjust).

\subsection{Simulation of satellite data}

All the reference simulations include daily LAI time series that are used to simulate satellite data following Duchemin and Maisongrande (2002). In order to simulate error 
in the retrieval of LAI from remote sensing data, reference LAI is converted into reference NDVI by applying equation 1 in the direct mode, then a Gaussian error is added on NDVI. The difference between the reference and degraded NDVI is proportional to the NDVI value with a factor of on average $5 \%$. Finally, the equation 1 is applied in the inverse mode to get a data set that includes 25 scenarios of degraded LAI.

In a second step, the sky conditions are described using a random number generator and the characteristics of cloudiness derived from the analysis of the meteorological data set (see $§ 2.3$.$) . The cloud occurrence probability at sowing date initialises the procedure,$ while the transition probabilities allows to simulate change in sky condition (e.g. from cloud-free to cloudy) from one day to the next during the period of simulation. The number of cloudy days ranges on average from $27 \%$ to $35 \%$ between the 25 scenarios.

Finally, data are removed on a regular basis according to various revisit capabilities of Earth Observations Systems. We considered four possibilities of satellite revisit time frequency : every day, every 5 days, every 10 days and every 15 days. The frequencies of 1 and 5 days correspond to what can be obtained by large field-of-view sensors such as VEGETATION, MODIS or MERIS, which provide a global observation of the word at $1 \mathrm{~km}$ spatial resolution. A repetitivity of 10 or 15 days simulate the capabilities of well-known SPOT-HRV and LANDSAT-TM high spatial resolution missions.

Since we have crossed 25 scenarios of cloudiness and noise and 4 frequencies, the algorithm results in 100 scenarios of degraded LAI time series with disrobed and inaccurate values. The number of remaining data from sowing to maturity knows large variations with the satellite time revisit frequency $(\mathrm{F})$; it ranges between 64 and 95 for $\mathrm{F}=1$, from 8 to 21 for $\mathrm{F}=5$, from 4 to 11 for $\mathrm{F}=10$, and from 2 to 8 for $\mathrm{F}=15$. Since we 
used a Gaussian number generator, the average error on NDVI may differ from one scenario to the next, especially when the number of remaining data in the time series is low; it varies between 2 to $10 \%$ between the different scenarios for $F=15$. It is important to note that the resulting noise is much larger on LAI (between 10 and 25\%) and that the degraded LAI is overestimated compared to the reference LAI at high values. This is due to the fact that the relationship between NDVI and LAI is exponential (see equation 1).

\subsection{Degraded simulations}

The algorithm used to simulate satellite data provides 100 time series of degraded LAI which are used to obtain degraded simulations by applying the calibration and driving approaches introduced in $\S 3.1$ and $\S 3.2$, respectively. These approaches have been tested with each of the degraded LAI time series as an input, with the readjustment of :

- the rate of foliage production in the case of SC1 method,

- the four parameters of the simple model that controls the leaves partitioning and senescence in the case of the SD4 method,

- all the seven parameters of the simple model in the case of the SD7 method.

In these simulations, the others parameters of the STICS model are kept constant to the values used in the reference simulations. 


\section{Results and discussions}

The performances of the STICS model to simulate yield and wheat evapotranspiration was intensively investigated in Hadria et al (2005). In this section, we present only some comparison between obtained results when the model is calibrated or driven both with field (i.e. reference simulations) and simulated satellite (i.e degraded simulations) LAI data. The reference simulations were compared to field observations while the degraded simulations were tested against the reference simulations. The evaluation was based on statistical moments which were applied successively for each scenario and for the three variables we focus on, i.e. LAI, AET and yield. The equations of Efficiency (EFF), Root Mean Square Error (RMSE), Mean Percentage Error (MPE) and Mean Bias Error (MBE) are given in the appendix B. By considering well-chosen subsets of scenarios, various comparative analyses have been performed between the variables, between the satellite time revisit frequency and the methods. Since the difference between the SD4 and SD7 are generally subtle, the comparison often focuses on the differences between SC1 and SD4 methods.

\subsection{Reference simulations}

Figure 4 shows the LAI time courses of the reference simulations corresponding to the SC1 and SD4 methods, and in Table 1 we summarised the statistics found between simulated and observed values for LAI and AET. Not shown here, the LAI time courses were similar for SD4 and SD7 methods (driving approach). This is due to the fact that the numerous available field-observations (symbols in Figure 4) allow to adjust all the parameters of the simple model.

[Insert Figure 4 about here] 
[Insert Table 1 about here]

Looking at LAI in Figure 4 and Table 1, one can see first that both approaches works quite correctly : RMSE is lower than $0.23 \mathrm{~m}^{2} \cdot \mathrm{m}^{-2}$ and EFF is larger than 0.98 . These results are in agreement with those reported in other studies ( e.g.: Clevers et al .2002, Panda et al. 2003). We conclude that the sets of parameters chosen for the adjustment are appropriate to simulate accurately the LAI time course. In particular, the thermal durations used in the SC1 method appear adapted to the wheat variety of the field of study. However, the LAI time course obtained with the SD4 method is more accurate than that obtained with the SC1 method, by a factor around 2 on MBE, MPE and RMSE (Table 1). This was expected, since the number of parameters that were adjusted is much larger for the driving than for the calibration approach. Under the conditions of this study, the simple model has allowed to better track the observations than the STICS model.

According to the statistics displayed in Table 1, the average level and seasonality of AET appear well reproduced with both approaches. The bias between observation and simulation is low, around $0.12 \mathrm{~mm} \mathrm{day}^{-1}$, a value which is under the range of error encountered with any AET measurement devices. However, the error can be large at a daily step (RMSE around $0.53 \mathrm{~mm} \mathrm{day}^{-1}$, MPE around 13.2\%). Further analyses have revealed that the error is reduced at a 10-day step (MPE around 9\%, RMSE around 0.25 $\mathrm{mm}$ day $^{-1}$ ). These errors are consistent with that of others crop modelling studies (Ben Nouna et al. 2000, Zhang et al. 2004, and Rodriguez et al. 2004). This last result would especially benefits for the monitoring of AET with remote sensing data and crop models. Indeed, the period of ten days may be more appropriate since it is adapted for 
the management of irrigation water while cloud-free imagery could be available at this time step given the characteristics of earth observing systems and cloudiness.

For grain yield, STICS predicts $1.95 \mathrm{t} \mathrm{ha}^{-1}$ with the SC1 method and $2.04 \mathrm{t} \mathrm{ha}^{-1}$ with the SD4 method. Thanks to the calibration of the grain filling stage we have performed, both of these values are in accordance with the observed yield (around $2 \mathrm{tha}^{-1}$ ). The difference between observed and simulated values, around $2.5 \%$, stepped out of the resolution of the model and an exact value cannot be retrieved from simulation. Furthermore, it appears that yield is firstly sensitive to crop temperature, with two distinct effects : 1) accumulated crop temperatures control the occurrence and the length of the reproductive phase, and 2) high temperatures, larger than $32^{\circ} \mathrm{C}$, cancel the grain filling during the reproductive phase. We illustrate these two effects in Figure 5 where the time course of grain yield is drawn along with maximal crop temperature for the reference simulations obtained with $\mathrm{SC1}$ and SD4 methods. For the calibration approach, the beginning of the grain filling stage is delayed by 2 days compared to the driving approach. This is due to slight differences in the thermal duration from plant emergence to grain filling stages between the methods. Furthermore, due to hot climate at the end of the season (after day 133 in Figure 5), the maximal crop temperatures are generally larger than the $32^{\circ}$ threshold and the grain filling is most often null. Looking at the day 145 in Figure 5, with a maximal crop temperature that is slightly lower (SC1 method) or slightly larger (SD method) than $32^{\circ}$, shows how this threshold is open to criticism. Indeed, this value might be adapted since it corresponds to standard wheat parameters of STICS, which has been determined for temperate variety.

[Insert Figure 5 about here] 
Despite the minor limitation regarding the yield simulation, these results show that the STICS model can simulate correctly crop evapotranspiration and grain yield with few parameters adapted or optimised. They coincide with the conclusions we have reached both in the semi-arid Valley of Yaqui in Mexico (Rodriguez et al. 2004) and in the Marrakech/Haouz plain (Hadria et al. 2005). This allows to consider these three first simulations as references in order to evaluate the degraded simulations we obtained with time series of LAI derived from simulated satellite data.

\subsection{Degraded simulations : $L A I$ and $A E T$}

An example extracted from the case of a satellite revisit time frequency of 5 days is first presented to detail the results obtained with satellite simulated LAI. In this example we focus on the result obtained with SC1 and SD4 method for the scenarios 10 to 20 since they illustrates for a large part all the results we obtained. Figure 6 shows the statistics on LAI and AET found for each of these 11 scenarios, while Figure 7 presents the corresponding simulation of LAI.

[Insert Figure 6 about here]

A first look at the statistics in Figure 6 shows that the degraded simulations performed generally well : EFF is generally close to one with a minimum value of 0.80 , the MPE ranges from 4 to $33 \%$. These results are globally acceptable, but differences appear between the methods and between the variables.

There are large differences between the calibration and driving approaches in the statistics displayed in Figure 6. When looking at the LAI, MPE and RMSE are much lower for the SC1 method than for the SD4 method. The difference is on average of a factor 2.2, e.g. RMSE is on average $0.17 \mathrm{~m}^{2} \cdot \mathrm{m}^{-2}$ for $\mathrm{SC} 1$ and $0.37 \mathrm{~m}^{2} \cdot \mathrm{m}^{-2}$ for SD4. 
However, it can reach a factor 4 for particular scenarios such as the simulations 11 and 14 highlighted with labels in Figure 7. The bias is on average 0.04 and 0.08 for SC1 and SD4 methods, respectively. It is positive because degraded LAI values are slightly larger than the reference ones in the procedure we used to simulate satellite data. The efficiency is on average 0.99 for SC1 method with a minimum value of 0.96 while it is on average 0.93 for SD4 methods with a minimum value of 0.80 . According to this example, the calibration approach appears to work better than the driving approach. This is confirmed in Figure 7 : for the SC1 method, the seasonal pattern of LAI is highly constrained since key phenological stages (e.g. dates of maximal LAI, dates of beginning of senescence) have been kept constant to the values of the reference simulations; for the SD4 method, the LAI time courses may not be in phase with the reference ones, since the parameters which control the leaf partitioning (during plant growing) and senescence are adjusted for each scenario. The simulations number 11 and 14 highlighted with labels in Figure 7 furnish a good example of large LAI overestimation and shift in phase between degraded and reference simulation.

[Insert Figure 7 about here]

The trends in errors between the approaches we previously pointed out for LAI are similar for AET : the error for the SC1 method is lower than for the SD4 method by on average a factor 2. However, there are large differences between LAI and AET in terms of accuracy : the MPE ranges from 4 to $34 \%$ on LAI and from 1 to $10 \%$ on AET; the minimum efficiency is 0.80 for LAI and 0.97 for AET ; the maximum value of bias is 0.26 on LAI while it is only 0.13 on AET ; the RMSE is on average $0.30 \mathrm{~m}^{2} \cdot \mathrm{m}^{-2}$ on LAI and $0.16 \mathrm{~mm} \cdot \mathrm{day}^{-1}$ on AET, though these two variables know the same range of variation. Taking as an example the SD4 method, the scenarios 11 and 14 displays poor 
results on LAI (EFF around 0.8, MPE around 32\%), but quite acceptable results on AET (EFF around 0.97, MPE around 9\%).

It is important to note that the error in the simulation of LAI has a small effect on the simulation of AET. In order to quantify this, we display in Figure 8 the MPE on AET as a function of the error on LAI, with all the satellite time revisit frequencies on the same plot. Not surprisingly, it can be see in Figure 8 that the errors increases with the frequency and that the error is much lower for the SC1 than for the SD4 method. More interesting is that a clear relationship appears, showing that the error is larger for LAI than for AET by on average a factor 4. This is particularly visible for the SC1 method, because there is no scatter since the LAI time courses of reference and degraded simulations are completely in phase. The explanation is twofold. Firstly, the LAI variable have an opposite effect on plant transpiration and soil evaporation, e.g. overestimated LAI will result in overestimated transpiration but underestimated evaporation. Since AET is the sum of soil evaporation and plant transpiration, the LAI variation will generally result in a lower variation on AET. This statement depends on the soil water status, however. Secondly, wheat AET saturates at high LAI values because transpiration saturates and evaporation is strongly reduced (Brisson et al. 1998, Duchemin et al. 2005). Since large errors in simulated satellite data occur at high LAI values (§3.3.), they have a reduced impact on AET.

[Insert Figure 8 about here]

[Insert Figure 9 about here]

Figure 9 shows the MPE on LAI and AET as a function of the satellite revisit time frequency (F). It allows to confirm and generalise the example that have been 
previously discussed from Figures 6 to 8. It firstly appears that the calibration is much accurate than the driving approach : the general level of MPE is much lower for SC1 method than for SD methods, by a factor that varies from 40 to $80 \%$ according to the variable and the frequency.

Secondly, it is clear that the calibration approach is much robust than the driving approach (Figure 9). Looking at the AET variable, the increase of MPE between $\mathrm{F}=1$ and $\mathrm{F}=15$ is around $1 \%$ for the SC1 method and around 5\% for SD methods. This is due to fact that wheat phenology is much more constrained for SC1 method than for SD methods (see the example of LAI time courses in Figure 7). This is in agreement with the conclusion of Bannayan et al. (2003), which have pointed out that phenology is the first critical characteristics to be known for simulating the crop dynamics.

Figure 9 finally allows to detail how the error increases with $\mathrm{F}$ between the different methods. The error associated to the SC1 method knows a low increase excepted when $\mathrm{F}$ is larger than 10 for the LAI variable. The error of the SD4 method increases between $\mathrm{F}=1$ and $\mathrm{F}=5$, then between $\mathrm{F}=10$ and $\mathrm{F}=15$; it flats out between $\mathrm{F}=5$ and $\mathrm{F}=10$. The error associated to the SD7 method continuously increases with F. One can also note that the accuracy of the results can know the same order of variation between the methods than between the frequency, e.g. the variation of MPE on AET is around 1\% between the three methods for $\mathrm{F}=1$ as well as between $\mathrm{F}=1$ and $\mathrm{F}=15$ for the $\mathrm{SC} 1$ method.

Under the prevailing condition in this study, we conclude that the performance of the methods is firstly correlated to the numbers of parameters used in the optimisation procedure, especially when the satellite revisit capacities are poor $(\mathrm{F}=10$ and $\mathrm{F}=15$ in Figure 9). Whatever the variable or the frequency, the most accurate method appears to 
be SC1, followed by SD4 then SD7, which requires the adjustment of one, four and seven parameters, respectively. The explanation lies in the fact that the lower is the number of adjusted parameters the more constrained is the time course of LAI. The difference is clearly visible between the SC1 and SD4 methods in the example we previously discussed (see Figure 7).

Finally, an additional criterion has been introduced to evaluate the operationality of each method. Mathematically, a method of interpolation is more accurate when the number of parameters to be adjusted is lower than the point number to be interpolated. In this study, the accuracy of the simple model used to interpolate observed LAI values is higher when the number of observations is high, more than 4 observations in case of SD4 method and more than 7 in case of SD7 method. So, it is reasonable to state that a method is operational if the number of parameters to be adjusted is lower than the number of available observations. The success ratio criterion we defined counts the number of scenario that meets this requirement. This last criterion used in this study gives also, not surprisingly, the advantage to the SC1 method (Table 2). The SD4 method is still $100 \%$ operational except at the lowest revisit frequency $(\mathrm{F}=15)$, while the success ratio of the SD7 methods knows a sharp decrease after $\mathrm{F}=10$ to reach a very low value $(20 \%)$ when $\mathrm{F}=15$. It is clear that the simple model with seven adjusted parameters is oversized.

[Insert Table 2 about here]

\subsection{Degraded simulations Yield}

[Insert Figure 10 about here] 
Figure 10 shows the yield predicted by STICS for the scenarios 10 to 20 and a satellite time revisit frequency of 5 days, i.e. for the example we discussed in Figures 6 and 7. Yield is always close to the reference values, but with different groups of values. To explain these variations, it is important to keep in mind that the thermal duration that control the various reproductive phases are common to all the simulations. Under these conditions, the yield mainly varies with the crop temperature, which stops the grain filling when its daily maximal value is larger than $32^{\circ} \mathrm{C}$. (see Figure 5). Let us refer to as $\mathrm{N}$ the number of days for which the maximal crop temperature has reached this threshold. $\mathrm{N}$ varies according to the time course of LAI, which have a slight effect on crop temperature. Taking the example of the $\mathrm{SC} 1$ method, $\mathrm{N}$ is 13 for the reference simulation, and either 12 or 13 for the degraded simulations. When $\mathrm{N}$ is 13 , the yield is close to the reference value (around $1.95 \mathrm{t} \mathrm{ha}^{-1}$ ), while it is larger (around $2.15 \mathrm{t} \mathrm{ha}^{-1}$ ) when $\mathrm{N}$ is 12 since the grains are filled one day more. Consequently, there are two groups of yield values for the degraded simulations that are particularly visible in Figure 10-a. This results in a lack of coherence from a scenario to the next and with an average overestimation of the reference value. The same explanation can be given for the SD4 method (Figure 10-b) with larger variation of $\mathrm{N}$ compared to the SC1 method.

[Insert Figure 11 about here]

Figure 11 displays the average and standard variation of yield for each method as a function of the satellite time revisit frequency. In all cases, the estimate of yield is acceptable, with an average error that is always less than $10 \%$ of the reference value and a standard deviation, which varies from 10 to $20 \%$ of the reference value. However, no hierarchy clearly appears between the methods and between the frequencies. The explanation lies in the critical role of the maximal crop temperature variable previously 
discussed in Figures 4 and 9. It would be necessary to revisit the formalism and/or the parameters associated to the grain filling process to reach some clear conclusions on yield estimate in the conditions of the semi-arid Haouz plain.

\section{Conclusion}

The first comparison between simulation and field observations confirms the capacity of STICS to accurately simulate wheat phenology (LAI) and actual evapotranspiration (AET). This is an important step towards the monitoring of yield and water balance as well as the scheduling of irrigation in the Haouz plain using the STICS model. Indeed, AET is the dominant loss term of the soil water balance in semi-arid areas, while water stress is an important limiting factor of crop production, especially when it occurs during the period from flowering to grain filling. After calibration, STICS has also provided with accurate estimates of yield. However, the effect of crop temperature on grain filling was found unrealistic for the climatic conditions of the Haouz plain. This study pointed out the necessity of a further adaptation of the STICS formalisms and parameters to the wheat variety cropped in the field of study.

The main objective of this study was to test two approaches, which consist in calibrating or driving the STICS model with LAI derived from remote sensing data. This study has allowed to compare the two approaches for satellite time revisit frequency from 1 to 15 days. All the simulations provide with acceptable results, but large differences appear between the variables, between the approaches and between the frequencies.

When tested against field observations, it was shown that the two approaches works accurately to retrieve LAI, AET and yield. Error in LAI and AET for the reference 
simulations were low and under the range of many values found in the literature. When using satellite simulated data, large differences appear in the accuracy between LAI, AET and Yield. The ratio of the LAI errors to the AET errors was always found around 4. The explanation is twofold : 1) soil evaporation compensates plant transpiration at low LAI values ; 2) soil evaporation is negligible and plant transpiration saturates at high LAI values. On the opposite, errors on yield estimates have shown no correlation with these variables, because the effect of crop temperature was found dominant and non-adapted to the field of study. Yield prediction ranges from $-5 \%$ and $22 \%$ of the reference values. However, under the conditions that prevail in this study, it was impossible to establish trends or hierarchy between the approaches or between the revisit capabilities of Earth observation systems.

The performance of LAI and AET simulations has been found very different according to the used approach. These variations are explained by the quantity of a priori information given to the model, which is opposite to the number of parameters that require to be adjusted. The calibration approach, which requires the adjustment of only one parameter, provides the best accuracy. This accuracy is larger for this approach than for the driving approach by a factor that varies from 1.25 to 2.5 according to the variables of interest (LAI or AET) and the satellite time revisit frequency. Furthermore, the calibration approach is operational even with the lowest satellite time revisit frequency. However, the robustness of the calibration approach could be limited by the fact that it needs an annual adjustment of the rate of foliage production.

The accuracy of LAI and AET simulations has been also found directly related to the satellite revisit time frequency. Not surprisingly, the daily frequency gives always the best results on the estimates of LAI and AET with no strong differences between the 
approaches. The calibration approach was found the most accurate at a higher frequency. This method appeared particularly robust: the ratio of the errors on AET between a 15-day and a daily frequency is about 1.5 for the calibration approach while it is about three for the driving approach. Under the low cloudiness conditions of the Marrakech-Haouz plain, a good compromise for the satellite revisit capacity appears to be the 10-day frequency. According to this study, this frequency allows an accuracy of around $10 \%$ and $18 \%$ on LAI, around 3 and $4.5 \%$ on AET, for the calibration and driving approach, respectively.

Finally, it is important to note that all the observations that have been used to calibrate and evaluate the simulations are derived from a single field with a particular environment (soil, climate) and no water stress. A validation on additional conditions in the plant characteristics or the environmental stress would be necessary to confirm these statistics. Additionally, the models used in this study are not evaluated on an independent data set. Consequently, this study is essentially a curve-fitting exercise. The studied field was characterized by a low yield, which matches that observed on average for Morocco. However, a local calibration of the yield could be necessary to apply the studied approaches over other site in the world. 


\section{Acknowledgment}

This study was conducted within the framework of the IRD/Sud-Med project, with support from the European Union 5th Framework through two INCO-MED Programmes : WATERMED (http://www.uv.es/ucg/watermed) and IRRIMED (http://www.irrimed.org/). The authors would like to acknowledge the Sud-Med technical partners, and especially ORMVAH (Office Regional de Mise en Valeur Agricole du Haouz). We are greatly indebted to the PNTS (Programme National de Télédétection Spatiale). The authors specially thank F. Ruget and N. Brisson (INRA, Avignon, France) for their kind and helpful discussions on the STICS model. 


\section{Appendix A: A simple model to interpolate leaf are index}

This model has been developed in the frame of the SudMed project. The modelling of the vegetation dynamics is based on the mathematical formalisms developed by Monteith (1965) for the photosynthesis and the biomass production, and Maas (1993) for the conversion of the assimilats in green leaves. The vegetation module is initialised with two parameters: an initial green LAI associated to the day of plant emergence. Along the vegetative period, solar radiation is converted into photosynthetically active radiation using a climatic efficiency coefficient of 0.48 (Varlet-Grancher et al. 1982). A part of this radiation is absorbed and converted into aerial dry biomass according to the light-use-efficiency parameter and the specific leaf area coefficient, which was measured at field $\left(0.022 \mathrm{~m}^{2} \mathrm{~g}^{-1}\right)$. The dry aerial biomass is partitioned between green leaves and stems following the two parameters function suggested by Maas (1993). The leaves senescence is modelled according to a classical degree-day approach, with two parameters that control the starting date and the rate of yellowing, respectively. The senescence is supposed total when the green LAI is lower than the initial value associated to plant emergence.

Seven parameters are required to run this model : the initial LAI value, the day of plant emergence, the light-use-efficiency, the two parameters used in the partitioning function, and the two parameters used in the senescence function. However, reasonable assumptions can be made on the initial conditions and many studies have deal with the light-use-efficiency (Sinclair and Muchow 1999, Jamieson et al. 1998b, Hammer and Wright 1994). Consequently, it is expected that this model would furnish a good LAI interpolator by fitting only the four parameters used to simulate partitioning and senescence. 


\section{Appendix B: Statistic moments}

The following statistics variables were used : the efficiency (EFF), which judges the performances of simulation data; the Root Mean Square Error (RMSE) and the mean percentage error (MPE), which measures the variation of predicted values around observed values; the Mean Bias Error (MBE), which indicates the average deviation of the predicted values from the measured values. Mathematical expressions of these variables are given by equations B 1 to B 4:

$$
\begin{aligned}
& E F F=1-\frac{\sum_{i=1}^{n}\left(y_{i \mathrm{mod}}-y_{i o b s}\right)^{2}}{\sum_{i=1}^{n}\left(y_{i_{o b s}}-\bar{y}_{\text {obs }}\right)^{2}} \\
& R M S E=\sqrt{\frac{1}{n} \sum_{i=1}^{n}\left(y_{i \bmod }-y_{i o b s}\right)^{2}} \\
& \left.M P E=\frac{\left[\sum_{i=1}^{n}\left(\frac{\left|y_{i_{o b s}}-y_{i_{\mathrm{mod}}}\right|}{y_{i o b s}}\right) 100\right.}{n}\right] \\
& M B E=\bar{y}_{\bmod }-\bar{y}_{\text {obs }}
\end{aligned}
$$

Where $y_{i \text { mod }}$ and $y_{i o b s}$ are individual values of modelled and observed variables, $\bar{y}_{\text {mod }}$ and $\bar{y}_{o b s}$ are their averages, and $n$ is the number of available observations. 


\section{References}

ALLEN, R.G., PEREIRA, L.S., RAES, D. and SMITH, M., 1998, Crop Evapotranspiration: Guidelines for computing crop Water requirements, pp. 1300 (Rome: FAO Irrigation and drainage, Paper 56).

ALLEN, R.G., 2000, Using the FAO-56 dual crop coefficient method over an irrigated region as part of an evapotranspiration intercomparison study. Journal of Hydrology, 229, pp. 27-41.

ARKIN, G.F., MAAS, S.J. and RICHARDSON, C.W., 1980, Forecasting grain sorghum yields using simulated weather data and updating techniques. Transactions of the $A S A E$, 23, pp. 676-680.

ASNER P.A., BRASWELL, B.H., SCHIMEL, D.S. and WESSMAN, C.A., 1998, Ecological research needs from multiangle remote sensing data. Remote Sensing of Environment, 63, pp. 155-165.

ASRAR, G., FUCHS, M., MANEMASU, E.T. and HATFIELD, J.L., 1984, Estimating absorbed photosynthetic radiation and leaf area index from spectral reflectance in wheat. Agronomy Journal, 76, pp. 300-306

BANNAYAN, M., CROUT, N.M.J. and HOOGENBOOM, G., 2003, Application of the CERES-wheat model for within-season prediction of winter wheat yield in the United Kingdom. Agronomy Journal, 95, pp. 114-125.

BARET, F., GUYOT, G. and MAJOR, D.J., 1989, Crop biomass evaluation using radiometric measurements. Photogrammetria, 43, pp. 241-256. 
BARET, F. and GUYOT, G., 1991, Potentials and limits of vegetation indices for LAI and APAR assessment. Remote Sensing of Environment, 35, pp. 161-173.

BARET, F., WEISS, M. and TROUFLEAU, D., 2002, Assimilation of multi temporalspectral-directional reflectance data in a NPP model: a case study and comparison of sampling schemes for different sensors, Final Report, Ecole Supérieure d'Agriculture.

BEN, NOUNA, B., KATERJI, N. and MASTRORILLI, M., 2000, Using the CERESMaize model in a semi arid Mediterranean environment. Evaluation, of model performance. European journal of agronomy, 13, pp. 309-322.

BOEGH, E., THORSEN, M., BUTTS, M.B., HANSENA, S., CHRISTIANSEN, J.S., ABRAHAMSEN, P., HASSGER, C.B., JENSEN, N.O., VAN DER KEUR, P., REFSGAARD, J.C., SCHELDE, K., SOEGAARD, H. and THOMSEN, A., 2004, Incorporating remote sensing data in physically based distributed agrohydrological modelling. Journal of Hydrology, 287, pp. 279-299.

BRISSON, N., MARY, B., RIPOCHE, D., JEUFFERY, M.H., RUGET, F., NICOULlAUD, B., GATE, P., DEVIENNE-BARET, F., ANTONIOLETTI, R., DURR, C., RICHARD, G., BEAUDOIN, N., RECOUS, S., TAYOT X., PLENET, D., CELLIER P., MACHET, J.M., MEYNARD, J.M. and DELÉCOLLE, R., 1998, STICS: a generic model for the simulation of crops and their water and nitrogen balances, I. Theory and parametrization applied to wheat and corn, Agronomie, 18, pp. 311-346.

BRISSON, N., RUGET, F., GATE, F., LORGEOU, J., NICOULLARD, B., TAYOT, X., PLENET, D., JEUFFROY, M-H., BROUTHIER, A., RIPOCHE, S., MAY, B. 
and JUSTED, E., 2002, STICS: a generic model for he simulation of crops and their water and nitrogen balances, II. Model validation for wheat and maize. Agronomie, 22, pp. 69-92.

BRISSON, N., GARY, C., JUSTES, E., ROCHE, R., MARY, B., RIPOCHE, D., ZIMMER, D., SIERRA, J., BERTUZZI, P., BURGER, P., BUSSIERE, F., CABIDOCHE, Y.M., CELLIER, P., DEBAEKE, P., GAUDILLERE, J.P., HÉNAUlT, C., MARAUX, F., SEGUIN, B. and SINOQUET, H., 2003, An overview of the crop model STICS. European Journal of Agronomy, 18, pp. 309332.

CHEHBOUNI, A., ESCADAFAL, R., DEDIEU, G., ERROUANE, S., BOULET, G., DUCHEMIN, B., MOUGENOT, B., SIMONNEAUX, V., SEGHIERI, J. and TIMOUK F., 2003, A multidisciplinary program for assessing the sustainability of water resources in semi-arid basin in Morocco: SUDMED. In $E G S-A G U-E U G$ Joint Assembly, 6-11 April 2003, Nice (France).

CHERN, J.-S., LEE, L.-C., WANG, H.-C. and CHU, F.-H., 2001, An Introduction to NSPO and ROCSATs Missions. In $3^{\text {rd }}$ IAA Symposium on Small Satellites for Earth Observation, 2 - 6 April 2001, Berlin, (Germany).

CLEVERS, JAN G. P. W., VONDER, O. W., JONGSCHAAP, R.E. E; DESPRATS, JF., KING, C., PREVOT, L. and BRUGUIER, N., 2002, Using SPOT data for calibrating a wheat growth model under Mediterranean conditions. Agronomie, 22, pp. 687-694.

COMBAL, B., BARET, F., WEISS, M., TRUBUIL, A., MACÉ D., PRAGNERE, A., MYNENI, R., KNYAZIKHIN, Y. and WANG, L., 2003, Retrieval of canopy 
biophysical variables from bidirectional reflectance: Using prior information to solve the ill-posed inverse problem. Remote Sensing of Environment, 84, pp. 115.

DEDIEU, G., CABOT, F., CHEHBOUNI, A., DUCHEMIN, B., MAISONGRANDE, P., BOULET G. and PELLENQ, J., 2003, RHEA: a micro-satellite mission for the study and modelling of land surfaces through assimilation techniques. In $E G S-$ AGU - EUG Joint Assembly, 6-11 April 2003, Nice (France).

DEMARTY, J., OTTLE, C., BRAUD, I., OLIOSO, A., FRANGI, J.P., BASTIDAS, L.A. and GUPTA, H.V., 2004, Using a multiobjective approach to retrieve information on surface properties used in a SVAT model. Journal of Hydrology, 287, pp. 214236.

DUCHEMIN, B. and MAISONGRANDE, P., 2002, Normalisation of directional effects in 10-day global syntheses derived from VEGETATION/SPOT: I- Investigation of concepts based on simulation. Remote Sensing of Environment. 21, pp. 90-100.

DUCHEMIN, B., HADRIA, R., RODRIGUEZ, J-C, LAHROUNI, A., KHABBA, S., BOUlet, G., MOUGENOT, B., MAISONGRANDE, P. and WATTS, C., 2003. Spatialisation of a Crop Model using Phenology derived from Remote Sensing Data. In $23^{\text {th }}$ International Geoscience And Remote Sensing Symposium (IGARSS), 21-25 July 2003, Toulouse (France).

DUCHEMIN, B., HADRIA, R., ER-RAKI, S., BOULET, G., MAISONGRANDE, P., CHEHBOUNI, A., ESCADAFAL, R., EZZAHAR, J., HOEDJES, J., KARROUI, H., KHABBA, S., MOUGENOT, B., OLIOSO, A., RODRIGUEZ, J-C., SIMONNEAUX, V. and TIMOUK, F., Monitoring wheat phenology and 
irrigation in Center of Morocco : on the use of relationship between evapotranspiration, crops coefficients, leaf area index and remotely-sensed vegetation indices. in press in Agricultural and Water Management.

FRANÇOIS, C., CAYROL, P., KERGOAT, L., MOULIN, S. and DEDIEU, G., 2001, Assimilation techniques of remote sensing measurements into vegetation models: overview, limits and promises. In $8^{\text {th }}$ Symposium on Physical Measurements and Signatures in Remote Sensing of International Society for Photogrammetry and Remote Sensing (ISPRS), 8-12 January 2001, Aussois (France).

GUÉRIF, M. and DUKE, C., ,1998, Calibration of the SUCROS emergence and early growth module for sugar beet using optical remote sensing data assimilation, European Journal of Agronomy, 9, pp. 127-136.

GUÉRIF, M. and DUKE, C., 2000, Adjustment procedures of a crop model to the site specific characteristics of soil and crop using remote sensing data assimilation, Agriculture, Ecosystems and Environment, 81, pp. 57-69.

GUTMAN, G. and IGNATOV, A., 1995, Global land monitoring from AVHRR: potential and limitations. International Journal of Remote Sensing, 16, 23012309.

HADRIA, R., KHABBA, S., LAHROUNI, A., DUCHEMIN, B., CHEHBOUNI, A.G., OUZINE, L., CARRIOU, J., Calibration and validation of the STICS crop model for managing wheat irrigation in the semi-arid marrakech/Al Haouz Plain, Accepted for publication in The Arabian Journal for Science and Engineering, special issue "Potential Water Challenges and Solutions in the New Millennium in Arid Regions". 
HALL, F.G., TOWNSHEND, J.R. and ENGMANN E.T., 1995, Status of remote sensing algorithms for estimation of land surface parameters. Remote Sensing of Environment, 51, pp. 138-156.

HAMMER, G.L. and WRIGHT, G.C., , 1994, A theoretical analysis of nitrogen and radiation effects on radiation use efficiency in peanut, Australian Journal of Agriculture Research, 45, pp. 575-589.

HANSEN, S., JENSEN, H.E., NIELSEN, N.E. and SWENDEN, H., 1990, DAISY: soil plant atmosphere system model, pp. 1-272 (Copenhagen: The National Agency for Environmental Protection).

HARRIS, T.R. and MAPP, H.P. Jr., 1980, A control theory approach to optimum irrigation scheduling in the Oklahoma Panhandle, South Journal of Agricultural Economics, 12, pp. 165-171.

JACQUEMOUD, S., BACOUR, C., POILVÉ, H. and FRANGI, J-P., 2000, Comparison of Four Radiative Transfer Models to Simulate Plant Canopies Reflectance: Direct and Inverse Mode. Remote Sensing of Environment, 74, pp. 471-481.

JAMIESON, P.D., PORTER, J.R., GOUDRIAAN, J., RITCHIE, J.T., VAN KEULEN, H. and STOLL, W., 1998a, A comparison of the models AFRCWHEAT2, CERESWheat, Sirius, SUCROS2 and SWHEAT with measurements from wheat grown under drought. Field Crops Research, 55, pp. 23-44.

JAMIESON, P.D., SEMENOV, M.A., BROOKING, I.R. and FRANCIS, G.S., 1998b, Sirius: a mechanistic model of wheat response to environmental variation. European Journal of Agronomy, 8, pp. 161-179. 
Karrou, M., 2003, Conduite du blé au Maroc. Institut National de la recherche agronomique, pp. 1-57 (Rabat: INRA éditions).

KIMES, D.S., KNYAZIKHIN, Y., PRIVETTE, J.L., ABUELGASIM, A.A. and GAO, F., 2000, Inversion methods for physically-based models. Remote Sensing Reviews, 18, pp. 381-439.

KITE, G. W. and DROOGERS, P., 2000, Comparing evapotranspiration estimates from satellites, hydrological models and field data. Journal of Hydrology, 209, pp. 318.

MAAS, J. S., 1993, Parameterized model of gramineous crop growth: I- Leaf area and dry mass simulation. Agronomy Journal, 85, pp. 348-353.

MO, X., LIU, S., LIN, Z. and ZHAO, W., 2004, Simulating temporal and spatial variation of evapotranspiration over the Lushi basin. Journal of Hydrology, 285, pp. $125-142$.

MONTEITH, J.L., 1965, Evaporation and environment. In $19^{\text {th }}$ Symposia of the Society for Experimental Biology, Cambridge, University Press, pp. 205-234.

MOULIN, S., BONDEAU, A. and DELÉCOLLE, R., 1998, Combining agricultural crop models and satellite observations from field to regional scales. International Journal of Remote Sensing, 19, pp. 1021-1036.

MOULIN, S. and GUÉRIF, M., 1999, Impact of model parameter uncertainties on crop reflectance estimates: a regional case study on wheat. International Journal of Remote Sensing, 20, pp. 213-218. 
MOUlin, S., KergoAT, L., CAYROL, P., DEDIEU, G. and PRÉVOT, L., 2003, Calibration of a coupled canopy functioning and SVAT model in the ReSeDA experiment. Towards the assimilation of SPOT/HRV observations into the model. Agronomie, 22, pp. 681-686.

NELDER, J. A. and MEAD, R., 1965, A Simplex Method for Function Minimization. Computer Journal, 7, pp. 308-313.

OLIOSO, A., CHAUKI, H., COURAULT, D. and WIGNERON, J.P., 1999, Estimation of Evapotranspiration and Photosynthesis by Assimilation of Remote Sensing Data into SVAT Models. Remote Sensing of Environment, 68, pp. 341-356.

PANDA, R.K., BEHERA, S.K. and KASHYAP, P.S., 2003, Effective management of irrigation water for wheat under stressed conditions. Agricultural water management, 63, pp. 37-56.

PELLENQ, J. and BOULET G., 2004, A methodology to test the pertinence of remotesensing data assimilation into vegetation models for water and energy exchange at the land surface. Agronomie, 24, pp. 197-204.

PRÉVOT, L., CHAUKI, H., TROUFLEAU, D., WEISS, M., BARET, F. and BRISSON, N., 2003, Assimilating optical and radar data into STICS crop model for wheat. Agronomie, 23, pp. 297-303

RICHARDSON, A. J., WIEGAND, C.L., WANJURA, D.F., DUSEK, D. and STEINER, J.L, 1992, Multisite analyses of spectral-biophysical data for sorghum. Remote Sensing of Environment, 41, pp. 71-82. 
RITCHIE J.T. and OTTER S., 1985, Description and performance of CERES-wheat: a user-oriented wheat yield model, US department of agriculture ARS, 38, pp. 159175.

RODRIGUEZ, J.C., DUCHEMIN, B., HADRIA, R., WATTS, C., KHABBA, S., BOUlet, G., GARATUZA, J., CHEHBOUNI, A., LAHROUNI, A. and PALACIOS, E., 2004, Wheat yield estimation using remote sensing and the STICS model in the semi-arid valley of Yaqui, Mexico. Agronomie, 24, pp. 295304.

RUGET, F., BRISSON, N., DELECOLlE, R. and FAIVRE, R., 2002, Sensibility analysis of a crop simulation model, STICS, in order to choose the main parameters to be estimated. Agronomie, 22, pp. 133-158.

SCHMUGGE, T.J., KUSTAS, W.P., RITCHIE, J.C., JACKSON, T.J. and RANGO, A., 2002, Remote sensing in hydrology. Advances in Water Resources, 25 1367-1385.

SINCLAIR, T.R. AND MUCHOW., R.C., 1999, Radiation use efficiency. Advances in Agronomy, 35, pp. 215-265.

VERHOEF, W. and BACH, H., 2003, Remote sensing data assimilation using coupled radiative transfer models. Physics and Chemistry of the Earth, 28, pp. 3-13.

WEIR, A.H., BRAGG, P.I., PORTER, J.R. and RAYNER, J.H., 1984, A winter wheat crop simulation model without water or nutrient limitations. Journal of Agricultural Science, 102, pp. 371-382.

WEISS, M. and BARET, F., 1999, Evaluation of canopy biophysical variable retrieval performances from the accumulation of large swath satellite data. Remote Sensing of Environment, 70, pp. 293-306. 
WEISS, M., TROUflEAU, D., BARET, F., CHAUKI, H., PREVOT, L., OLIOSO, A., BRUGUIER, N. and BRISSON, N., 2001, Coupling canopy functioning and radiative transfer models for remote sensing data assimilation. Agricultural and Forest Meteorology, 108, pp. 113-128.

WILLIAMS, J.R., JONES, C.A., KINIRY, J.R. and SPANEL, D.A., 1989, The EPIC crop growth model. Transactions of the ASAE, 32, pp. 497-511.

ZHANG, Y.Q., YU Q., LIU, C.M., JIANG, J. and ZHANG, X., 2004, Estimate of winter wheat evapotranspiration under water stress with two semiempirical approaches. Agronomy Journal, 96, pp. 159-168. 
Table 1. Statistics associated to the reference simulations of LAI and AET with SC1 and SD4 methods

\begin{tabular}{|c|c|c|c|c|c|c|c|c|}
\hline & \multicolumn{4}{|c|}{$\operatorname{LAl}\left(\mathrm{m}^{2} / \mathrm{m}^{2}\right)$} & \multicolumn{4}{|c|}{ AET (mmiday) } \\
\hline & MBE & RMSE & EFF & MPE (†) & MBE & RMSE & EFF & MPE \\
\hline $\mathrm{SCl}$ & 0.1 & 0.23 & 0.98 & 14 & 0.11 & 0.49 & 0.75 & 12.3 \\
\hline SD4 & 0.06 & 0.13 & 0.99 & 8 & 0.13 & 0.56 & 0.68 & 13.8 \\
\hline
\end{tabular}

$(*)$ values calculated for LAI larger than $0.5 \mathrm{~m}^{2} / \mathrm{m}^{2}$. 
Table 2. Success ratio of SC1, SD4 and SD7 methods as the function of the satellite time revisit frequency $(\mathrm{F})$.

\begin{tabular}{lcccc}
\hline & F $=1$ & $F=5$ & $F=10$ & $F=15$ \\
\hline SC1 & $100 \%$ & $100 \%$ & $100 \%$ & $100 \%$ \\
SD4 & $100 \%$ & $100 \%$ & $100 \%$ & $84 \%$ \\
SD7 & $100 \%$ & $100 \%$ & $68 \%$ & $20 \%$ \\
\hline
\end{tabular}




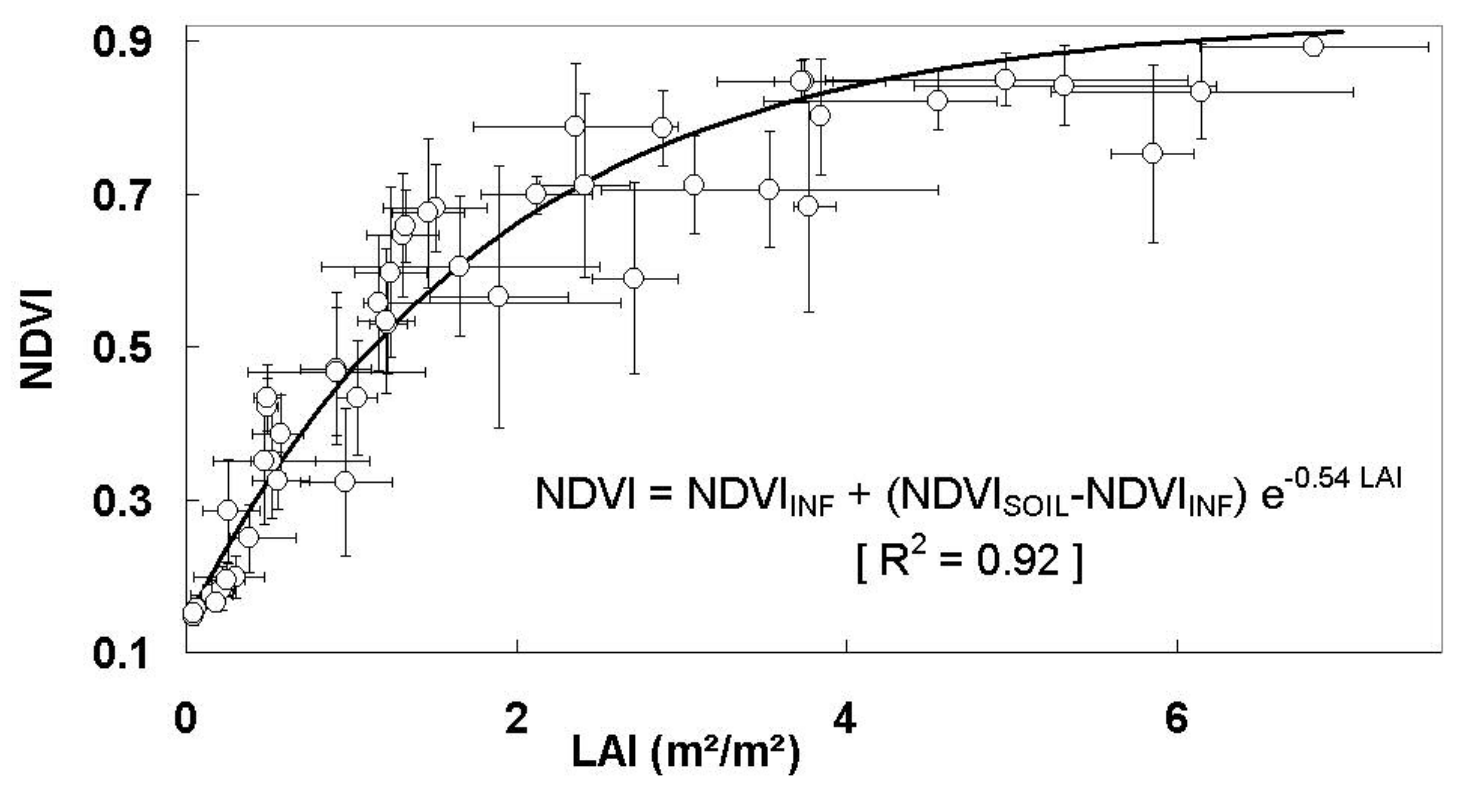

Figure 1. LAI-NDVI relationship. Symbols are centred on field-averaged LAI and NDVI values. Horizontal bars are minimum and maximum LAI values observed within fields. Vertical bars are the standards deviation of NDVI. An exponential relationship is fit on the scatterplot with infinitely dense canopy $\left(\mathrm{NDVI}_{\mathrm{INF}}\right)$ and soil $\left(\mathrm{NDVI}_{\mathrm{SOIL}}\right)$ values adjusted according to specific observation (they worth 0.93 and 0.14 , respectively). 


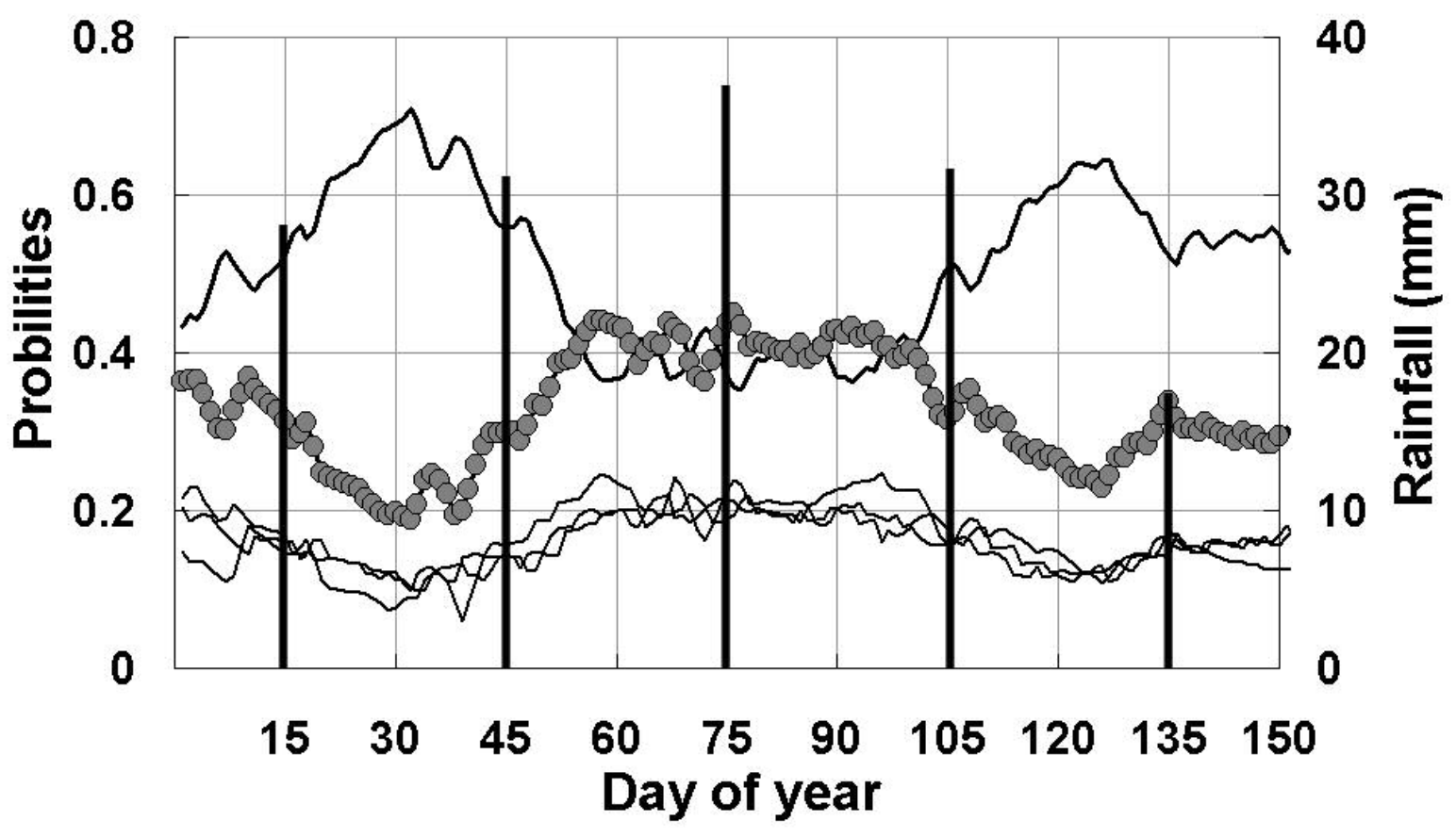

Figure 2. Cloud occurrence probability (symbols) and transition probabilities (lines) of the sky status (cloud-free or cloudy) in the Marrakech-Haouz plain from January to May. The thick line highlights the probability of transition from cloud-free to cloud-free. Vertical bars show the mean monthly precipitation in Marrakech during the last century. 


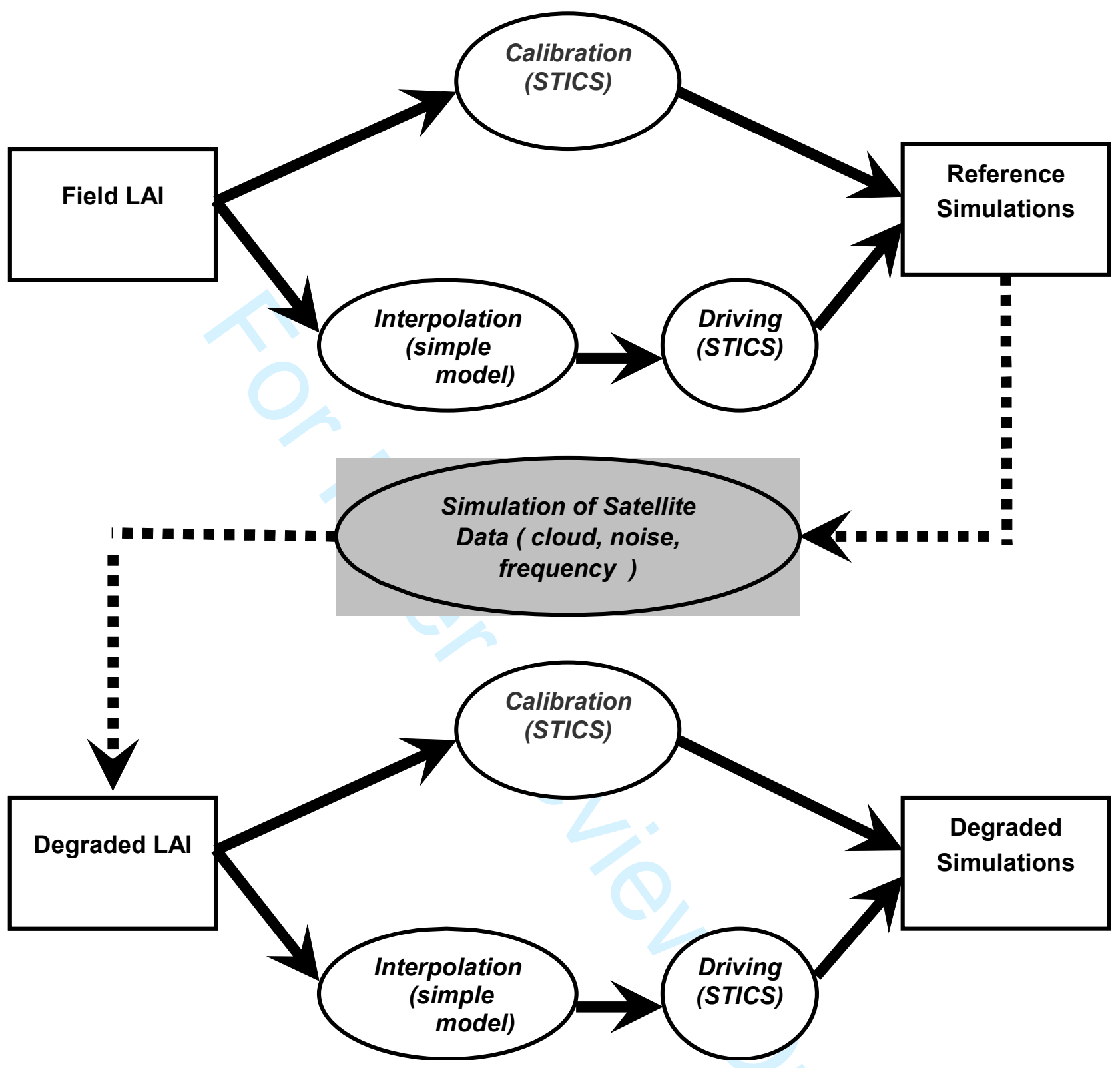

Figure 3. Simplified diagram of the methodology. 


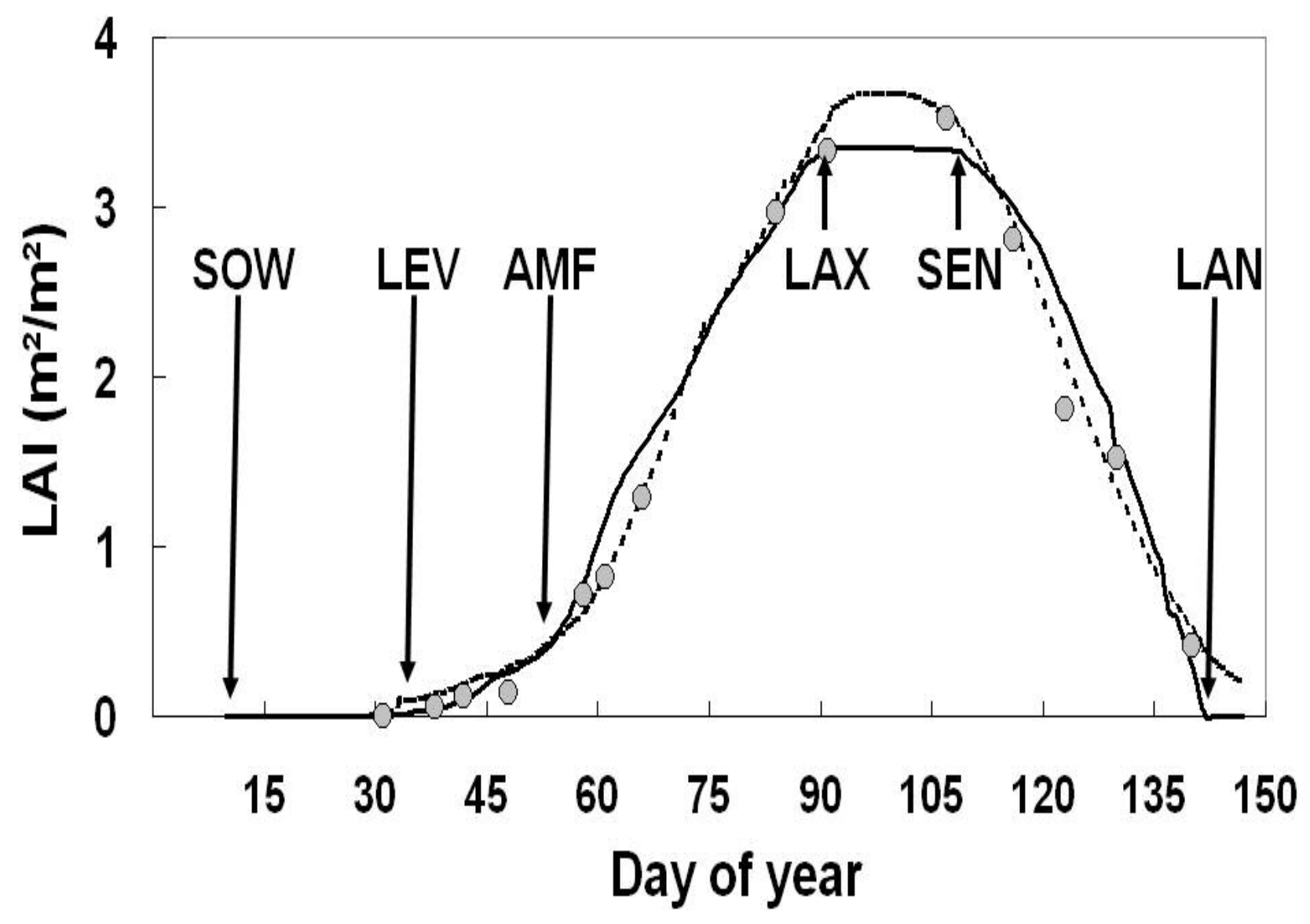

Figure 4. Reference simulations of LAI with SC1 (solid line) and SD4 method (dotted line) along with field LAI (symbols). The labels highlight the STICS phenological stages that control the time courses of LAI for the SC1 method : SOW = sowing date ; $\mathrm{LEV}=$ plant emergence; $\mathrm{AMF}=$ beginning of the stems elongation; $\mathrm{LAX}=$ maximum LAI; SEN = beginning of leaves senescence; LAN = total yellowing. 


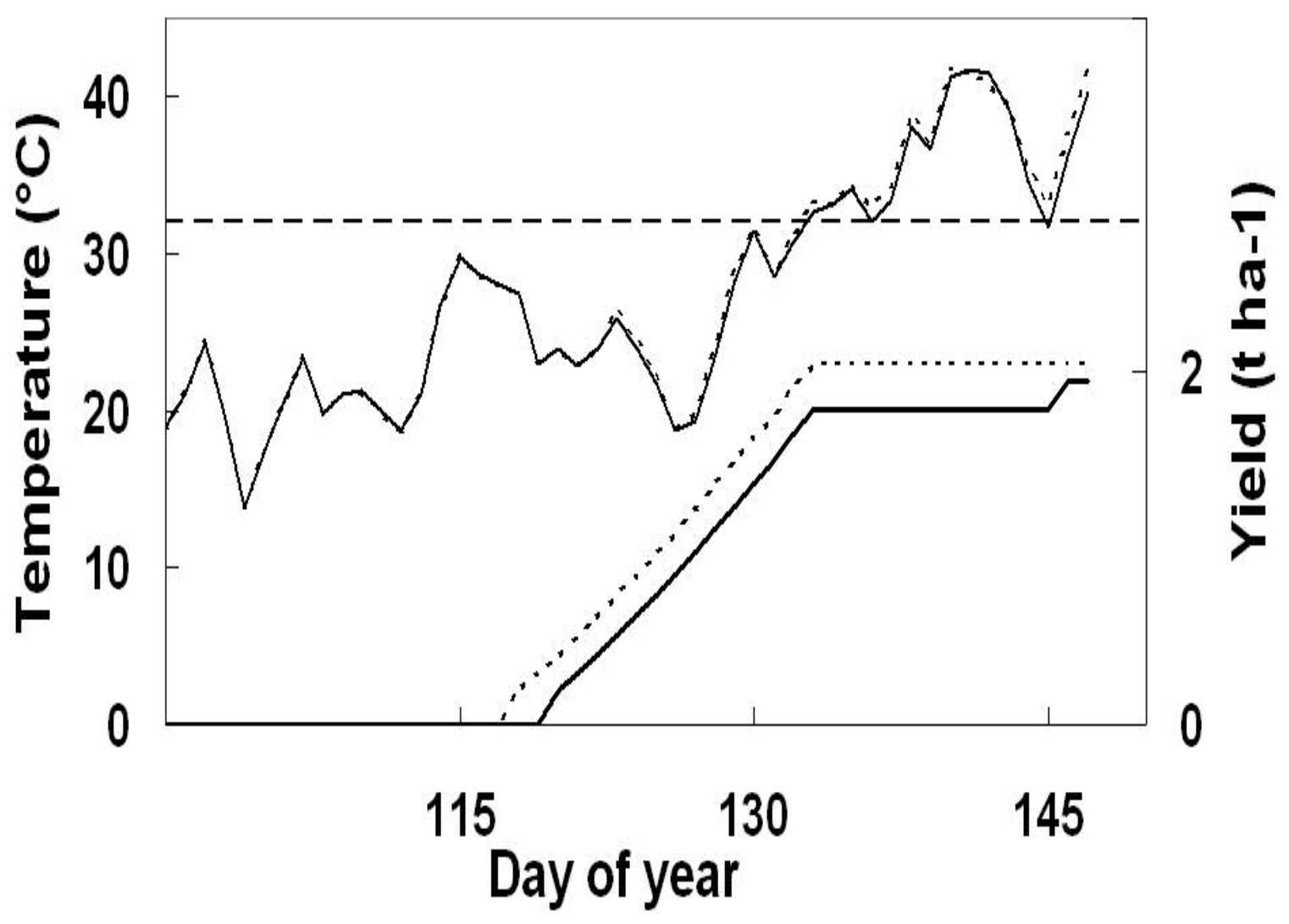

Figure 5. Grain yield and maximal crop temperature time courses in the reference simulations, with SC1 (solid line) and SD4 (dotted line) methods. The horizontal dotted line highlights the temperature threshold used to stress grain filling. 

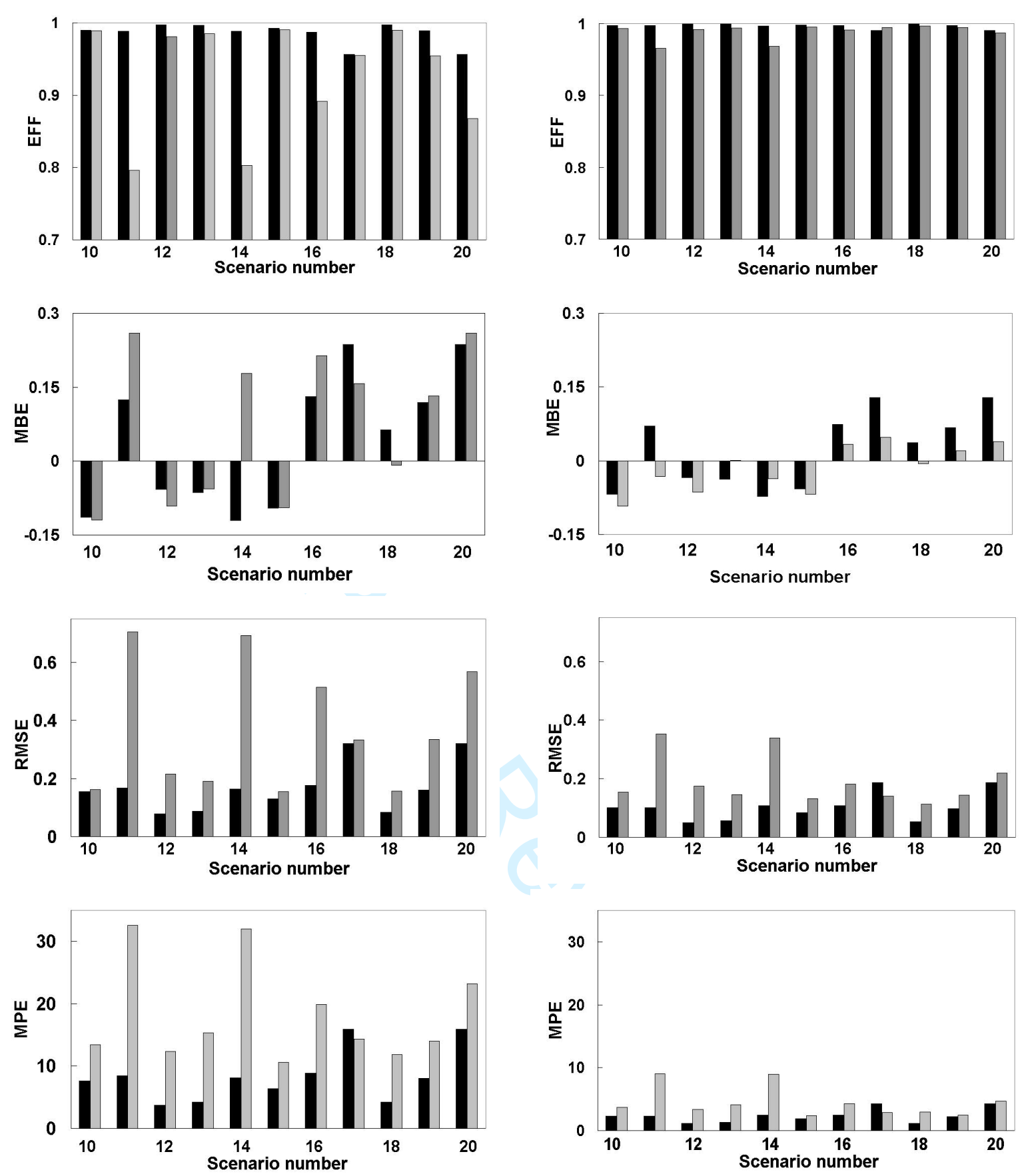

Figure 6. Statistic moments associated to the retrieval of LAI (left Figures) and AET (right Figures) in degraded simulations, with SC1 (black bars) and SD4 (grey bars) methods: $\mathrm{EFF}=$ efficiency, $\mathrm{MBE}=$ Mean Bias Error, RMSE $=$ Root Mean Square Error and $\mathrm{MPE}=$ mean percentage error. These results correspond to scenarios of cloudiness numbered 10 to 20 and to a satellite time revisit frequency of 5 days. 

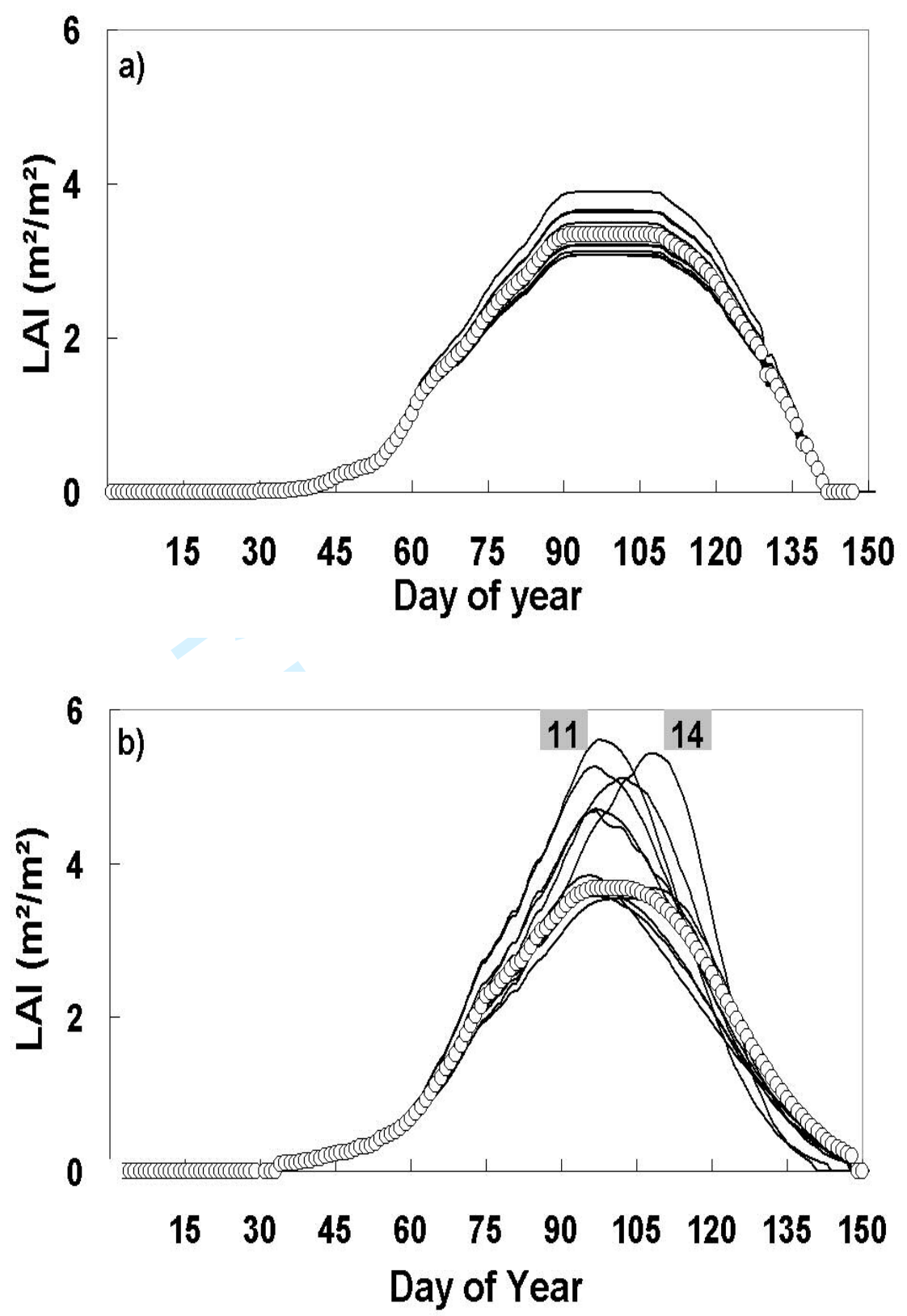

Figure 7. Times courses of LAI in degraded (lines) and reference (symbols) simulations : a) SC1 method; b) SD4 method. The degraded simulations correspond to scenarios of cloudiness numbered 10 to 20 and to a satellite time revisit frequency of 5 days (same as Figure 6). For the SD4 method (Figure b), the labels highlight the scenarios numbered 11 and 14, which displays the worst statistics moments (see greys bars in Figure $6)$. 

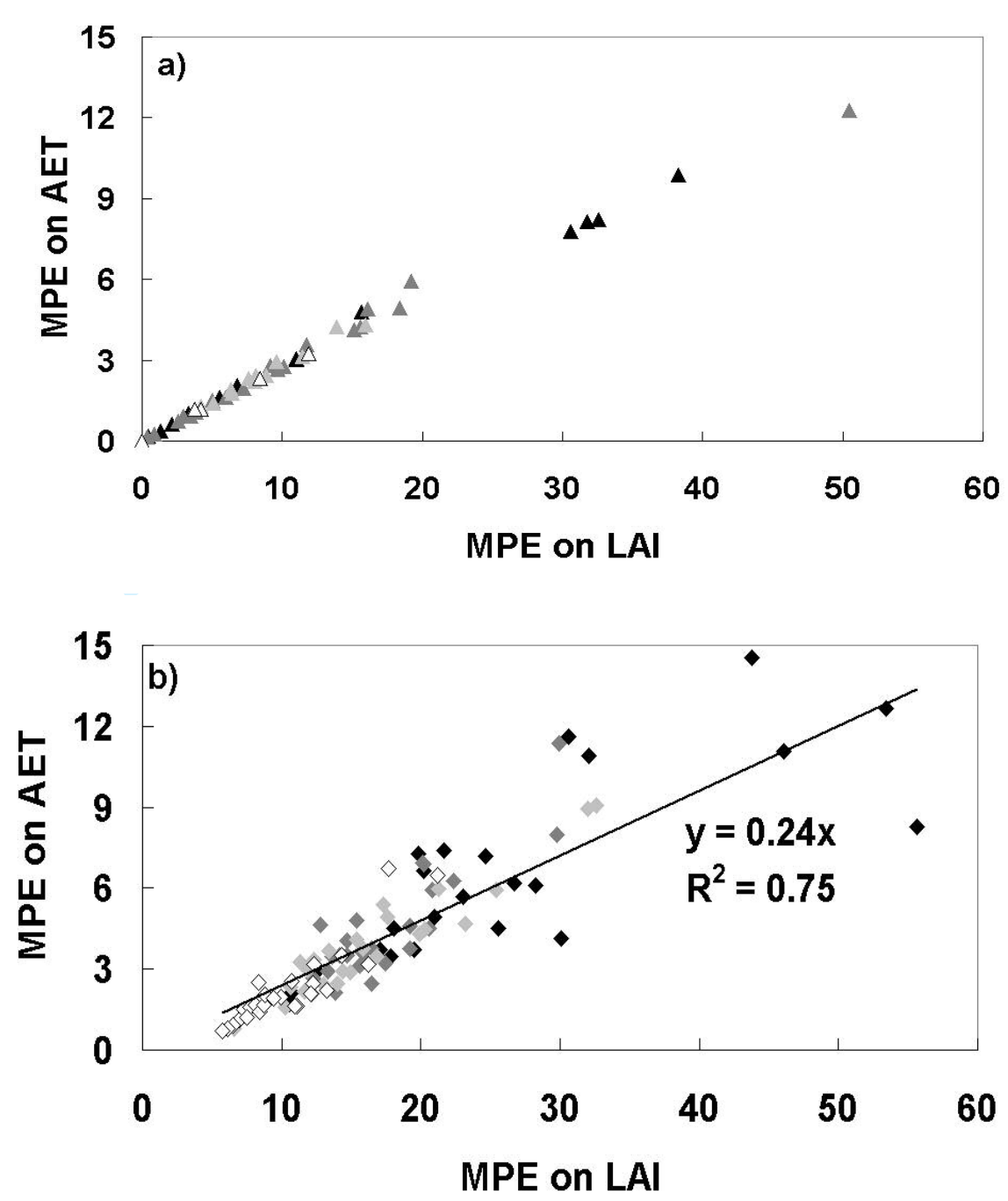

Figure 8. Mean Percentage Error (MPE) in the degraded simulations of AET and LAI: a) SC1 method, b) SD4 method. White, light grey, dark grey and black symbols corresponds to the various satellite time revisit frequency : $F=1, F=5, F=10$ and $\mathrm{F}=15$, respectively. 

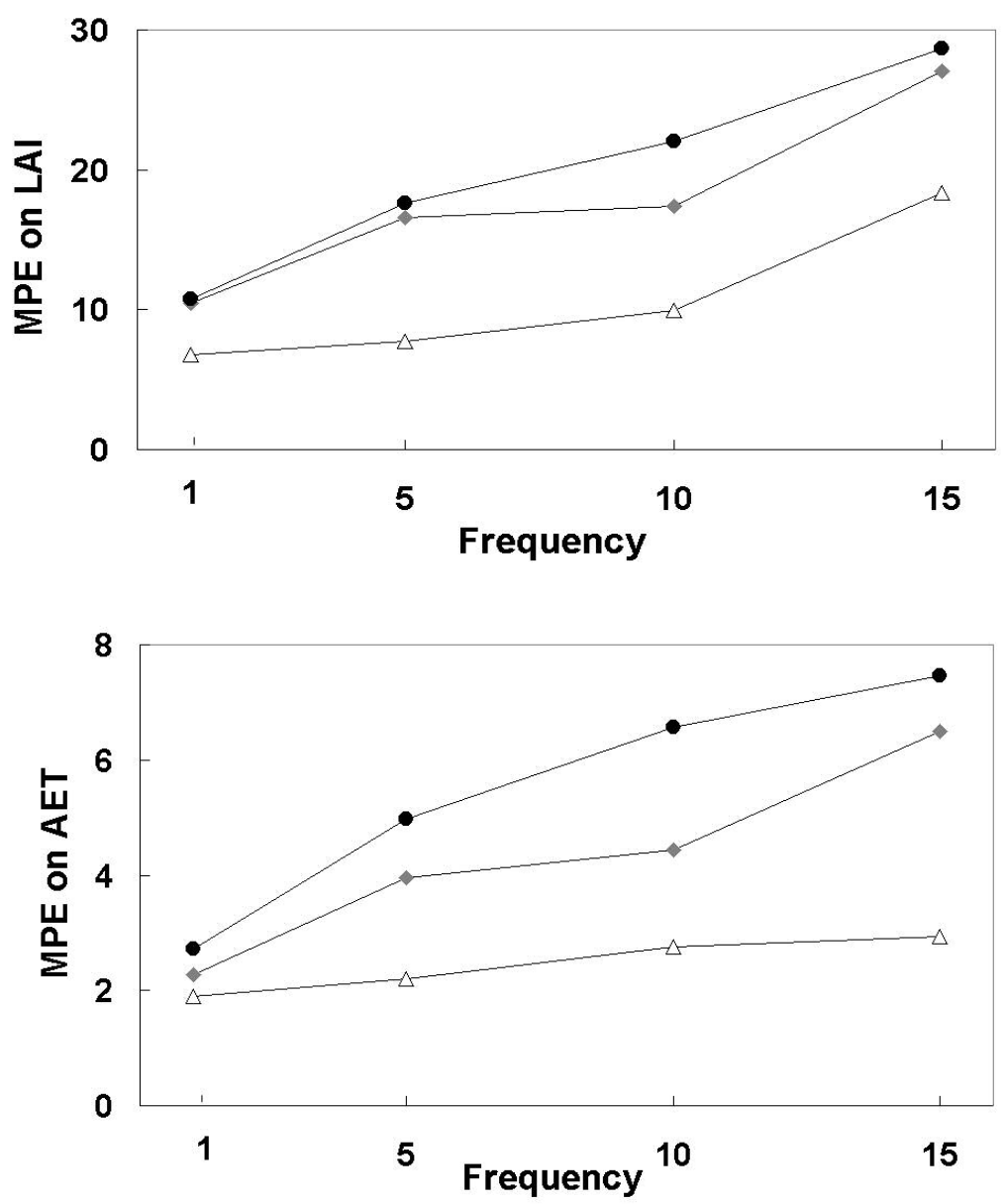

Figure 9. Mean percentage error on LAI (top) and on AET (bottom) as a function of the satellite time revisit frequency, for SC1 (triangles), SD4 (lozenges) and SD7 (circles) methods. Each symbol corresponds to an average over the 25 scenarios of cloudiness. 

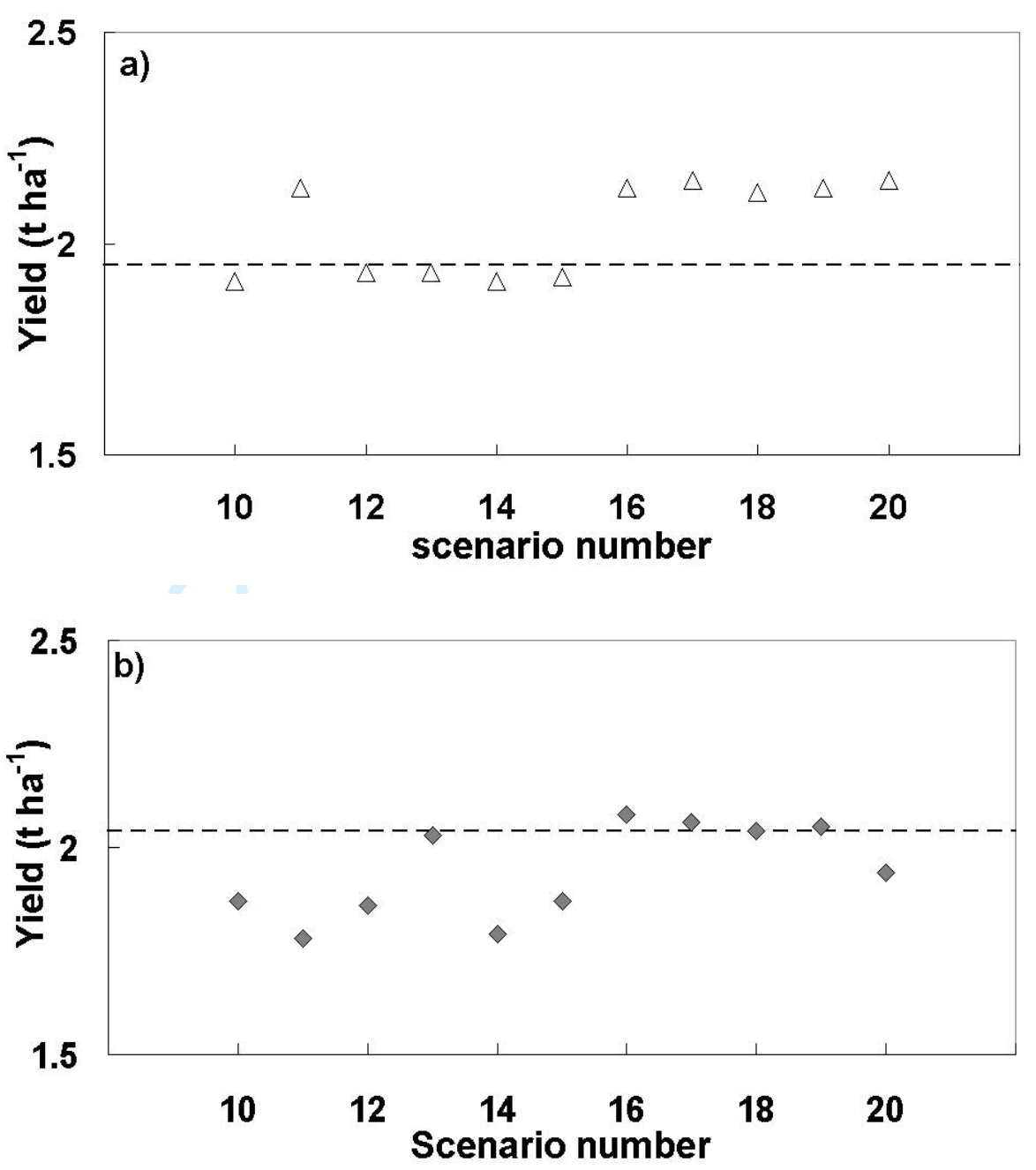

Figure 10. Yield values in degraded simulations, with : a) SC1 method; b) SD4 method. Horizontal dotted lines highlight the values obtained for the reference simulations. The degraded simulations correspond to scenarios of cloudiness numbered 10 to 20 and to a satellite time revisit frequency of 5 days (same as Figures 5 and 6). 

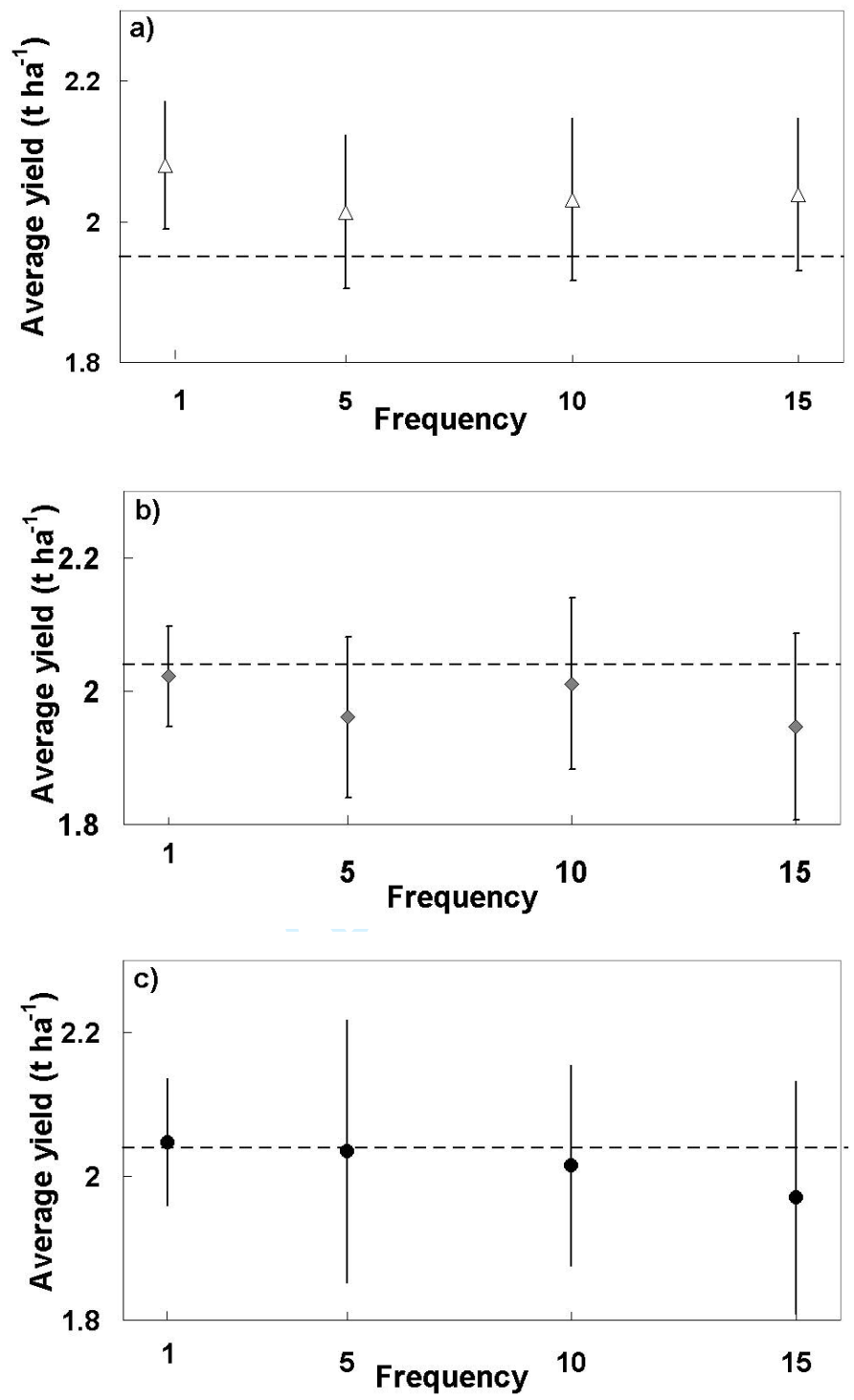

Figure 11. Average (symbols) and standard deviation (vertical lines) of yield values in degraded simulations as function of the satellite time revisit frequency, with: a) SC1 method; b). SD4 method; c) SD7 method. Dotted horizontal lines highlight the values obtained for the reference simulations. 